\title{
New, goal-directed approach to renal replacement therapy improves acute kidney injury treatment after cardiac surgery
}

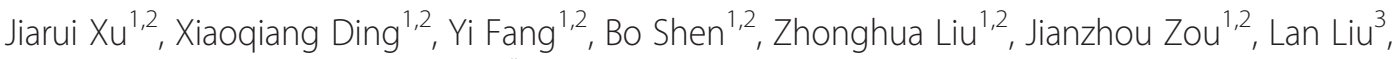 \\ Chunsheng Wang ${ }^{3}$ and Jie Teng ${ }^{1,2^{*}}$
}

\begin{abstract}
Aim: The aim of this study was to compare the efficacies of goal-directed renal replacement therapy (GDRRT) and daily hemofiltration (DHF) for treating acute kidney injury (AKI) patients after cardiac surgery.

Methods: In our retrospective study, we included 140 cardiac surgery AKI patients who were treated with renal replacement therapy (RRT) from 2002 to 2010. Two patient groups, which comprised 70 patients who received DHF from January 2002 to September 2008 and 70 patients treated with GDRRT from October 2009 to September 2010 were pair-wise compared regarding clinical outcomes, as well as the incidence of adverse events.

Results: In-hospital and 30-day mortality rates were $45.7 \%$ and $41.4 \%$ in the GDRRT and $48.6 \%$ and $54.3 \%$ in the DHF group, respectively, but without statistically significant differences. GDRRT patients needed statistically significantly shorter hospital and intensive care unit (ICU) stays, less frequent RRT, and shorter RRT sessions, whereas, of 11 analyzed renal outcome parameters, 6 values, including percentage of complete renal recovery and time for complete renal recovery, were significantly superior in the GDRRT group at the time of discharge. There was no significant difference in the incidence of adverse events within the initial 72 treatment hours between the 2 groups. Hospitalization expenses were less in GDRRT group than in DHF group.
\end{abstract}

Conclusion: The GDRRT approach is superior to DHF for improving renal outcome, as well as reducing the time and cost of RRT therapy, for cardiac surgery AKI patients.

Keywords: Cardiac surgery, Acute kidney injury, Goal-directed renal replacement therapy, Daily hemofiltration

\section{Background}

Cardiac surgery is a major cause of AKI in critically ill patients [1,2], and mortality among cardiopulmonary bypass patients who need RRT after cardiac surgery is reported to be $60-70 \%$ [3]. Although RRT is important in saving critically injured AKI patients, there is no consensus regarding the optimal dose or form. There is insufficient evidence to show that continuous renal replacement therapy (CRRT) is better than intermittent renal replacement therapy (IRRT) $[4,5]$, and the efficacy of hybrid patterns, such as sustained low-efficiency dialysis (SLED), has not yet been

\footnotetext{
*Correspondence: tengmuyao@gmail.com

'Department of Nephrology, Zhongshan Hospital, Shanghai Medical College, Fudan University, No 180 Fenglin Road, Shanghai 200032, China

${ }^{2}$ Shanghai Institute of Kidney and Dialysis, No 180 Fenglin Road, Shanghai 200032, China

Full list of author information is available at the end of the article
}

evaluated [6]. It is also unclear what the optimal dose is, although it is argued that, for critically injured AKI patients, the dose should be at least $35 \mathrm{ml} / \mathrm{kg} / \mathrm{h}$ of hemofiltration (HF) and an spKt/V value of 1.4 for hemodialysis (HD) [7]. However, recent results from the Acute Renal Failure Trial Network (ATN) study and the RENAL or IVOIRE trials did not suggest the superiority of high-dose intensive RRT $[8,9]$. Another issue is the optimal intervention time, and most clinicians believe that early RRT can improve outcomes, but there is no uniform standard as to when RRT should be initiated [10-12]. The idea of a goaldirected therapy (GDT) for critically ill patients was first raised in 1973 by Shoemaker [13], and hemodynamic GDT after surgery has been acknowledged as an effective measure against postoperative hospital-acquired infections [14]. In addition, various GDTs have been developed to 
achieve hemodynamic stability during and after cardiac $[15,16]$ and non-cardiac surgery [17], and Goldstein et al. have proposed an early goal-directed fluid therapy (EGDT) for fluid management of critically ill AKI patients [18]. The concept of a GDRRT was first proposed by Mehta et al. [19], but up to now, no detailed studies have been published about GDRRT. We have been using GDRRT since 2008, in which RRT goals were set up first, followed by determinations of ultrafiltration rates, dialysate compositions, and goal-directed anticoagulant therapies. GDRRT is supposed to be beneficial not only by providing extra treatments when they are specifically indicated, but also by allowing the earlier and guided use of fluids and preventing the delivery of unnecessary treatments or fluid removal when specific objectives have already been achieved. In this retrospective analysis, we compared the treatment outcomes of GDRRT and DHF in patients with AKI after cardiac surgery.

\section{Methods \\ Patients}

This retrospective, observational study was performed in a cohort of 140 adult patients who underwent cardiac surgery in our hospital from January 2002 to September 2010. The study included adult patients with AKI who required RRT after open heart surgery and survived longer than $72 \mathrm{~h}$ after surgery. Patients were excluded if they were under the age of 18 , received cardiac transplantation surgery, had end-stage renal disease (ESRD) before surgery, or received preoperative RRT due to any reasons. The DHF group included 70 patients who received DHF between January 2002 and September 2008, and the GDRRT group was comprised of 70 patients who were treated with GDRRT between October 2009 and September 2010. We used pair-wise comparisons between the 2 groups regarding clinical outcomes, as well as the incidence of adverse events. The study was approved by the Institutional Review Board of the Shanghai Zhongshan Hospital, which waived the requirement for informed consent for the retrospective review of RRT interventions after cardiac surgery. In our hospital, we practiced only DHF as a therapeutic strategy for treating AKI following cardiac surgery until 2008, and GDRRT was first introduced in October 2008. We used paired analysis in order to reduce the bias created by the different time periods. We collected data for a paired analysis from 70 patients who received DHF between January 2002 and September 2008, and from 70 patients who received GDRRT between October 2009 and September 2010. The main criteria for the paired analysis were equal type of surgery and severity of illness, according to acute physiology and chronic health evaluations (APACHE) II [20] and sepsis-related organ failure assessment (SOFA) scores [21].

\section{Data collection}

In addition to hemodynamic and laboratory data, baseline vital signs were also recorded in the first day of ICU admission and then daily after nephrology consultation. In addition, APACHE, II as well as SOFA scores and EuroScore values [22], were computed within the first $24 \mathrm{~h}$ after admission to the ICU, in order to assess the severity of the illness. AKI was defined as elevation of serum creatinine $(\mathrm{SCr}) \geq 26.4 \mu \mathrm{mol} / \mathrm{L}$ or $50 \%$ higher than the baseline within $48 \mathrm{~h}$, or urine output $<0.5 \mathrm{ml} / \mathrm{kg} / \mathrm{h}$ for more than $6 \mathrm{~h}$, and staged according to the AKI Network classification [23]. Sepsis was defined according to the American College of Chest Physicians/Society of Critical Care Medicine (ACCP/SCCM) Consensus Conference Committee [24]. Recovery of kidney function was considered to be complete if the $\mathrm{SCr}$ was less than $44 \mu \mathrm{mol} / \mathrm{L}$ above the baseline value or to be partial if the $\mathrm{SCr}$ remained higher than $44 \mu \mathrm{mol} / \mathrm{L}$ above the baseline value but the patient was not dialysis-dependent [9]. In-hospital mortality rates inside and outside the ICU within 30 days were the primary end-points of the trial. Secondary endpoints were ICU and hospital days, mechanical ventilation days, hospitalization expenses, hemodynamic stability, control of azotemia and volume overload, as well as renal function recovery.

\section{RRT methods}

DHF

The form, frequency, and time of each session, as well as the dose/ultrafiltration rate of DHF were fixed, assuming that patients were in a stable state at the time of DHF initiation and that their status did not change substantially. The indications for RRT initiation were as follows: (1) Serum $\mathrm{K}^{+} \geq 6.0 \mathrm{mmol} / \mathrm{L}$ and/or electrocardiogram abnormalities; (2) Arterial blood $\mathrm{pH} \leq 7.15$; (3) Urine output < $200 \mathrm{~mL} / 12 \mathrm{~h}$ when the first dose of furosemide was up to $80 \mathrm{mg}$ or the highest dose was up to $240 \mathrm{mg}$, or anuria; (4) Rapidly rising blood urea nitrogen (BUN) or SCr; (5) Refractory fluid overload with pulmonary edema; (6) Severe sepsis with septic shock. HF was performed with Baxter BM25 or Aquarius CRRT equipment using FILTRAL 20 (AN 69, $2.05 \mathrm{~m}^{2}$ surface, GAMBRO, Sweden). We used our hospital formula as a replacement fluid, and the ratio of pre- and post-dilution was two-thirds, with an ultrafiltration rate of $60-70 \mathrm{ml} / \mathrm{kg} / \mathrm{h}$. Vascular access was obtained with a dual-lumen HD catheter inserted into the internal jugular or femoral vein by the standard Seldinger technique. Either a loading dose of $1500 \mathrm{IU}$ heparin followed by an individual patient-adjusted anticoagulation regimen or no anticoagulation was used.

\section{GDRRT}

GDRRT cannot be defined as a fixed RRT strategy, and it is basically composed of HD, HF, and hemodiafiltration 
(HDF). All of these techniques were used, in order to achieve specific goals, and various parameters were monitored. The indications for RRT initiation were the same as for DHF. The patients received a central venous catheter capable of measuring central venous pressure (CVP), and oxygen saturation data were fed into a computerized ECG monitor, which also monitored heart and breathing rates, as well as blood pressure. Fluid intake and output was recorded every day, and urine output was recorded every $6 \mathrm{~h}$. Potential of hydrogen and arterial oxygen saturation were monitored by blood gas analysis at least every $4 \mathrm{~h}$. Blood biochemistry and other laboratory data were tested at least once every day. The usual HD or HF lasted about $4 \mathrm{~h}$ per session and were performed every day or every other day, but for all patients, the form, frequency, and time of each session and the dose/ultrafiltration rate were not standardized. The procedures were all performed with Baxter Aquarius equipment, using highly permeable membranes made of polyether sulfone $\left(1.7 \mathrm{~m}^{2}\right.$ or $1.4 \mathrm{~m}^{2}$ surface area, GAMBRO, Sweden) starting the first session with a small surface area filter and increasing the filter size in further sessions. The vascular access and replacement fluid were the same as for DHF, and the usual HF ultrafiltration rate was $25-35 \mathrm{ml} / \mathrm{kg} / \mathrm{h}$. The usual blood flow ranged from 100 to $250 \mathrm{ml} / \mathrm{min}$ and the dialysate flow was $8-10 \mathrm{~L} / \mathrm{h}$ for HD. In all GDRRT modalities, anticoagulation was performed with unfractionated heparin, low-molecular-weight heparin (LMWH), or no anticoagulation, according to the consulting nephrologists' decisions.

\section{GDRRT algorithm}

The goals of GDRRT are listed in Table 1, and they included immediate and ongoing goals. The immediate goals were correcting electrolyte disturbance and acidemia by providing bicarbonate or reducing hyperkalemia, controlling volume by removing fluid overload, and improving hemodynamic stability. Ongoing goals included maintenance of fluid balance, promoting renal recovery, weaning from vasopressors, maintenance of acid-base and electrolyte balances, and support of organ functions.

The treatment protocol was as follows (see Figure 1). The GDRRT strategy was decided before treatment, based on the severity of the illness. Hemodynamically stable patients in hypercatabolic state or with severe internal environment disturbance (defined as having a SOFA cardiovascular score of 0 to 2) received $\mathrm{HD}$ or $\mathrm{HDF}$, while patients without hypercatabolic state or severe internal environment disturbance or who were hemodynamically unstable (defined as having a SOFA cardiovascular score of 3 to 4) received HF. GDRRT was performed every day to achieve the goals listed in Table 1, and the frequency and duration of RRT sessions were determined depending on whether these goals were achieved. If the goals were not achieved (e.g., no solute control, severe electrolyte disturbance, refractory fluid overload, severe unstable hemodynamics), or in case of severe sepsis, acute respiratory distress syndrome (ARDS), or multiple organ dysfunction syndrome (MODS), the dose was increased and the usual HD and HF session times of about $4 \mathrm{~h}$ were extended to $8-10 \mathrm{~h}$ per session, or even $24 \mathrm{~h}$ if necessary. If the goals were achieved in the following days, the dose and frequency were reduced, and the time of each session was shortened. When patients receiving HD turned hemodynamically unstable (i.e., when the mean arterial pressure (MAP) was $\leq 65 \mathrm{mmHg}$, or the average cumulative daily variability of MAP was $\geq$ $30 \mathrm{mmHg}$ ) they were transitioned to HF, or continuous treatment was administered and vasopressors or vasodilators were given to maintain the MAP. The crossover from one to the other RRT modality was decided by nephrologists. The initial form of GDRRT included 57 usual HD and $13 \mathrm{HF}$ sessions, and the main reason for conversion from HD to HF was hemodynamic instability. During the course of treatment, 10 patients received continued HD/ HF because of sepsis or MODS, and only one patient received continued HDF for severe sepsis. The ultimate form of GDRRT was usual HD 53 times and HF 17 times.

\section{Statistical analyses}

Statistical analyses were performed using the SPSS software, version 16.0. Measurement data were expressed as means $\pm S D$ or median and quartile $[M(Q R)]$. Paired $\mathrm{t}$-test was used for comparing baseline characteristics of the 2 groups, and independent t-test was used for comparing outcomes, while chi-squared test was used to analyze categorical data. Logistic regression analysis was used to correct for confounding factors. $\mathrm{P}<0.05$ was considered as statistically significant.

\section{Table 1 The goals of GDRRT}

\begin{tabular}{|c|c|}
\hline Solute & $\mathrm{BUN} \leq 30 \mathrm{mmol} / \mathrm{L}$ \\
\hline Volume & $\begin{array}{l}\text { Urine output } \geq 0.5 \mathrm{ml} / \mathrm{kg} / \mathrm{h}, 24 \mathrm{~h} \text { fluid output } \geq 24 \mathrm{~h} \text { fluid intake in volume overload patients, controlled acute pulmonary edema, } \\
\text { reduction of peripheral edema, hematocrit } \geq 30 \%\end{array}$ \\
\hline $\begin{array}{l}\text { Electrolyte and } \\
\mathrm{pH}\end{array}$ & Electrolyte and acid-base parameters normal or near normal: $3.5<$ potassium $\leq 5.5 \mathrm{mmol}, 7.25 \leq \mathrm{pH}<7.45$ \\
\hline Hemodynamics & MAP $\geq 65 \mathrm{mmHg}$ without vasoactive drugs, CVP $\geq 8-12 \mathrm{mmHg}, \mathrm{SaO}_{2} \geq 93 \%$ \\
\hline
\end{tabular}




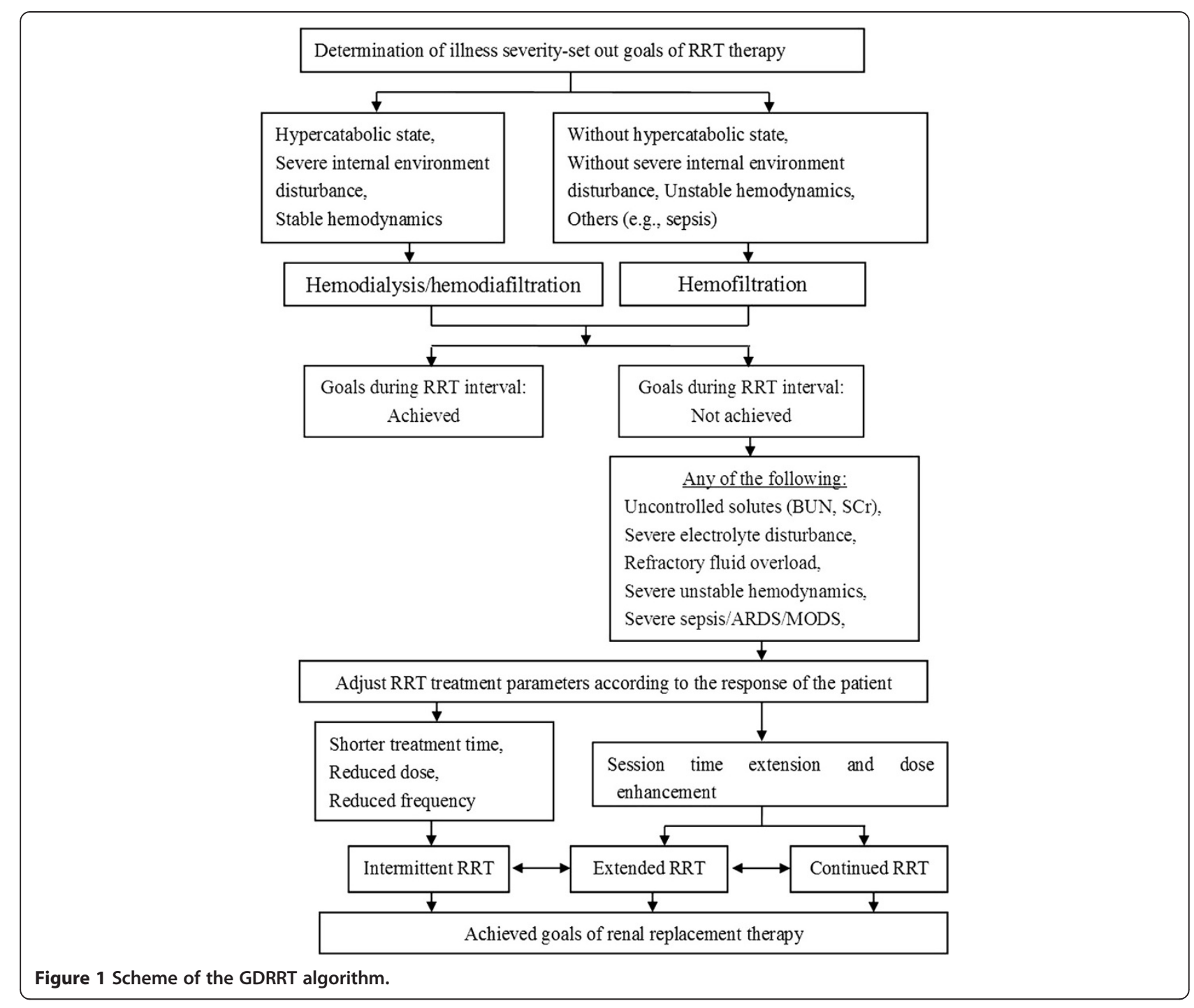

\section{Results}

Of the 140 patients, 70 underwent GDRRT, while the other 70 underwent DHF, and treatments in the 2 groups included 21 valve surgeries, 13 coronary artery bypass grafts (CABG), 19 thoracic aortic surgeries, 7 congenital heart surgeries, and 10 combined surgeries. The body mass index (BMI) in the GDRRT group was significantly lower than in the DHF group $(22.0 \pm 3.6$ vs. $23.8 \pm 4.6, \mathrm{P}=$ 0.025). Other baseline characteristics of the 2 groups were not significantly different (Table 2).

\section{Clinical outcomes}

After being adjusted by logistic regression, the in-hospital mortality in the GDRRT and DHF groups were $45.7 \%$ and $48.6 \%$, respectively $(\mathrm{P}=0.734)$. The 30 -day mortality was $41.4 \%$ and $54.3 \%$ in the GDRRT and the DHF groups, respectively. The median hours of ICU stay and mechanical ventilation days in the GDRRT group were significantly less than those in the DHF group (238.9 [119.9-483.8] vs.
360.0 [178.8-552.9] hours, $\mathrm{P}=0.026)$ and 6 [3-15] vs. 9 [619] days, respectively, $P=0.046$ ). There was no significant difference in median length of hospital stay between the 2 groups (25 [14-32] vs. 23 [13-36] days, $\mathrm{P}=0.998)$. The frequency of RRT and the mean duration of RRT sessions were longer in the DHF group (2 [1-6] vs. 4 [2-9], $\mathrm{P}=$ 0.018 and $5 \pm 1$ vs. $6 \pm 2$ hours, $\mathrm{P}<0.01)$. Hospitalization expenses were much higher in the DHF than in GDRRT group $(2307.7 \pm 430.8$ vs. $1515.4 \pm 461.5$ dollars, $\mathrm{P}<0.01)$ (Table 3).

\section{Renal outcomes}

The complete renal recovery rate was significantly higher in the GDRRT than in DHF group (37\% vs. $19 \%, \mathrm{P}=$ 0.016). The time for complete renal recovery was shorter in the GDRRT group ( $13 \pm 9$ vs. $22 \pm 14$ days, $\mathrm{P}=0.042$ ), whereas there were no significant differences in partial renal recovery rates in the 2 groups ( $9 \%$ vs. $15 \%, \mathrm{P}=$ 0.409). Both maximum $\mathrm{SCr}$ and $\mathrm{SCr}$ at hospital discharge 
Table 2 Baseline characteristics in the GDRRT and DHF groups

\begin{tabular}{|c|c|c|c|}
\hline & GDRRT $(n=70)$ & DHF $(n=70)$ & $P$ value \\
\hline Male (n/\%) & $70(64 \%)$ & 70 (71\%) & 0.366 \\
\hline Age (y) & $54 \pm 15$ & $55 \pm 15$ & 0.788 \\
\hline $\mathrm{BMI}\left(\mathrm{kg} / \mathrm{m}^{2}\right)$ & $22.0 \pm 3.6$ & $23.8 \pm 4.6$ & 0.025 \\
\hline DM (\%) & $16 \%$ & $7 \%$ & 0.118 \\
\hline HT (\%) & $33 \%$ & $44 \%$ & 0.165 \\
\hline NYHA III & $44 \%$ & $54 \%$ & 0.119 \\
\hline IV & $17 \%$ & $28 \%$ & 0.061 \\
\hline CPB duration (min) & $116 \pm 59$ & $134 \pm 52$ & 0.065 \\
\hline Aortic clamping duration (min) & $58 \pm 38$ & $57 \pm 32$ & 0.919 \\
\hline \multicolumn{4}{|l|}{ EurOSCORE } \\
\hline Low risk $(<3)$ & $12(17.1 \%)$ & $11(15.7 \%)$ & 0.820 \\
\hline Medium risk $(3-6)$ & $28(40 \%)$ & $25(35.7 \%)$ & 0.601 \\
\hline High risk (>6) & $30(42.9 \%)$ & $34(48.6 \%)$ & 0.497 \\
\hline Pre-op BUN (mmol/L) & $9.4 \pm 5.0$ & $8.9 \pm 6.7$ & 0.632 \\
\hline Pre-op SCr $(\mu \mathrm{mol} / \mathrm{L})$ & $112.1 \pm 74.8$ & $119.2 \pm 101.7$ & 0.639 \\
\hline \multicolumn{4}{|l|}{ Renal function before RRT } \\
\hline BUN (mmol/L) & $24.8 \pm 15.2$ & $27.3 \pm 16.2$ & 0.378 \\
\hline $\mathrm{SCr}(\mu \mathrm{mol} / \mathrm{L})$ & $334.5 \pm 148.9$ & $365.0 \pm 156.3$ & 0.250 \\
\hline $\mathrm{K}^{+}(\mathrm{mmol} / \mathrm{L})$ & $4.6 \pm 1.2$ & $4.5 \pm 1.3$ & 0.637 \\
\hline Oliguria (\%) & $48 \%$ & $44 \%$ & 0.683 \\
\hline \multicolumn{4}{|l|}{ AKIN before RRT (\%) } \\
\hline AKIN1 & $19 \%$ & $12 \%$ & 0.160 \\
\hline AKIN2 & $31 \%$ & $25 \%$ & 0.840 \\
\hline AKIN3 & $50 \%$ & $63 \%$ & 0.211 \\
\hline \multicolumn{4}{|l|}{ Time from ICU admission } \\
\hline to RRT (d) & $2(1,5)$ & $2.5(2,5)$ & 0.245 \\
\hline Sepsis (\%) & $18 \%$ & $23 \%$ & 0.381 \\
\hline Post-op APACHE II (24 h) & $21.9 \pm 5.4$ & $22.8 \pm 4.0$ & 0.266 \\
\hline \multicolumn{4}{|l|}{ Post-op SOFA (24 h) } \\
\hline Cardiovascular & $2.8 \pm 1.1$ & $2.6 \pm 1.0$ & 0.262 \\
\hline Respiratory & $2.4 \pm 1.0$ & $2.1 \pm 1.5$ & 0.164 \\
\hline Renal & $1.8 \pm 0.9$ & $1.7 \pm 1.2$ & 0.587 \\
\hline Entire SOFA Score & $10.8 \pm 2.5$ & $11.4 \pm 2.8$ & 0.183 \\
\hline
\end{tabular}

NYHA: New York Heart Association; Pre-op BUN: preoperative blood urea nitrogen; Pre-op Scr: preoperative serum creatinine; Post-op APACHE II (24 h): postoperative acute physiology and chronic health evaluation within the first $24 \mathrm{~h}$ after surgery; Post-op SOFA ( $24 \mathrm{~h}$ ): postoperative sepsis-related organ failure assessment within the first $24 \mathrm{~h}$ after surgery.

were higher in the DHF than in the GDRRT group $(561.0 \pm 239.2$ vs. $441.7 \pm 189.9 \mu \mathrm{mol} / \mathrm{L}, \mathrm{P}<0.001$, and $377.2 \pm 265.8$ vs. $275.5 \pm 164.3 \mu \mathrm{mol} / \mathrm{L}, \mathrm{P}=0.007$ ). There were no significant differences in maximum BUN and BUN at hospital discharge between the 2 groups ( $45.5 \pm$ 26.1 vs. $52.2 \pm 23.5 \mathrm{mmol} / \mathrm{L}, \mathrm{P}=0.226 ; 34.2 \pm 20.9$ vs. $29.6 \pm 17.7 \mathrm{mmol} / \mathrm{L}, \mathrm{P}=0.356$ ). Urinary volume after $72 \mathrm{~h}$ treatment was much greater in the GDRRT than in DHF group (1590 [450-3285] vs. $370[84,1365] \mathrm{ml}, \mathrm{P}=0.002$, and the time to oliguria resolution was shorter in the
GDRRT group $(2.5[1.0,3.8]$ vs. $5[2.5,8.5]$ days, $\mathrm{P}=$ 0.033) (Table 4).

\section{Hemodynamic parameters and safety of therapy}

The incidence of tachycardia and blood coagulation was significantly higher in the DHF than in the GDRRT group ( $79 \%$ vs. $60 \%, \mathrm{P}=0.018 ; 37 \%$ vs. $21 \%, \mathrm{P}=0.041$ ). There were no significant differences in MAP values and in the incidence of hypotension within the first $72 \mathrm{~h}$ of treatment between the 2 groups ( $82 \pm 12$ vs. $83 \pm 15 \mathrm{mmHg}, \mathrm{P}=0.664$; 
Table 3 Clinical outcomes of AKI patients in the GDRRT and DHF groups

\begin{tabular}{llll}
\hline & GDRRT $(\mathbf{n}=\mathbf{7 0})$ & DHF $(\mathbf{n}=\mathbf{7 0})$ & P value \\
\hline Hospital mortality (\%) & $45.7 \%$ & $48.6 \%$ & 0.734 \\
$30-\mathrm{d}$ mortality (\%) & $41.4 \%$ & $54.3 \%$ & 0.128 \\
Hospital stay (d) & $25(14,32)$ & $23(13,36)$ & 0.998 \\
ICU stay (h) & $238.9(119.9-483.8)$ & $360.0(178.8-552.9)$ & 0.026 \\
Mechanical ventilation days & $6(3-15)$ & $9(6-19)$ & 0.046 \\
Hospitalization expense (US\$) & $1515.4 \pm 461.5$ & $2307.7 \pm 430.8$ & $<0.01$ \\
RRT frequency & $2(1-6)$ & $4(2-9)$ & 0.018 \\
Duration of the RRT sessions & & & $< \pm 0.01$ \\
$\quad$ First (h) & $4 \pm 1$ & $5 \pm 2$ & $<0.01$ \\
$\quad$ Average (h) & $5 \pm 1$ & & \\
\hline
\end{tabular}

$38 \%$ vs. $40 \%, \mathrm{P}=0.862$ ). There was no significant difference in the daily ultrafiltration volume between the 2 groups (2112 \pm 768 vs. $1925 \pm 866 \mathrm{ml}, \mathrm{P}=0.179)$. The major anticoagulant medication in the DHF group was LMH (60\%), whereas in the GDRRT group, most patients (67\%) received no anticoagulation medication (Table 5).

\section{Discussion}

Although high-dose HF can help alleviate systemic inflammatory responses, it also can be harmful, due to its nonselective filtration, which can lead to the loss of heat, nutrients, and drugs [25]. In our study, GDRRT was mostly composed of HD, which can correct azotemia and acid-base disorders. High-dose HF was employed only for patients with severe sepsis, in order to support the internal environment and extra-renal organs, and to control inflammation and achieve hemodynamic stability, thereby improving immune paralysis and ventilatory functions. However, the incidence of sepsis in our study was only $18 \%$ for the GDRRT group and 23\% for the DHF patients lower than the previously reported values of $62.4 \%$ [9] and $46.8 \%$ in RTT patients after surgery. It has been suggested that HD often results in hemodynamic instability, but in this study, hypotension occurred at similar rates during intermittent HD sessions in the 2 groups, and tachycardia occurred more frequently in the DHF group. This can be explained by the low ultrafiltrate rate, which maintained stable hemodynamics in the GDRRT group, because the HD dose in the DHF group was significantly higher than in the GDRRT group (63.7 vs. $24.2 \mathrm{ml} / \mathrm{kg} / \mathrm{h}$ ). These values were also similar to the previously published values of $57 \mathrm{ml} / \mathrm{kg} / \mathrm{h}$ for IRRT and $42 \mathrm{ml} / \mathrm{kg} / \mathrm{h}$ for continued veno-veno $\mathrm{HF}(\mathrm{CVVH})$ treatment for cardiac surgery AKI patients [26]. The lower ultrafiltrate rate also reduced the need for anticoagulant medication and led to a lower incidence of blood coagulation in the GDRRT group.

The absence of complete renal recovery from AKI is one of the major risk factors of ESRD [27]. Bagshaw et al. reported that, of 240 critically ill patients who required dialysis, $32 \%$ were on chronic renal replacement therapy at hospital discharge and $22 \%$ persisted on dialysis after 1 year. Others also suggested that one of the purposes of RRT in treating AKI should be the promotion of renal function recovery and independence from

Table 4 Renal outcomes of AKI patients in the GDRRT and DHF groups

\begin{tabular}{|c|c|c|c|}
\hline & GDRRT $(n=70)$ & $\mathrm{DHF}(n=70)$ & $P$ value \\
\hline$\overline{M a x} \mathrm{BUN}(\mathrm{mmol} / \mathrm{L})$ & $52.2 \pm 23.5$ & $45.5 \pm 26.1$ & 0.226 \\
\hline $\operatorname{Max} \mathrm{SCr}(\mu \mathrm{mol} / \mathrm{L})$ & $441.7 \pm 189.9$ & $561.0 \pm 239.2$ & $<0.001$ \\
\hline BUN at discharge $(\mathrm{mmol} / \mathrm{L})$ & $29.6 \pm 17.7$ & $34.2 \pm 20.9$ & 0.356 \\
\hline Scr at discharge $(\mu \mathrm{mol} / \mathrm{L})$ & $275.5 \pm 164.3$ & $377.2 \pm 265.8$ & 0.007 \\
\hline $\mathrm{K}^{+}$after RRT ((mmol/L) & $4.5 \pm 0.8$ & $4.8 \pm 0.5$ & 0.008 \\
\hline Urinary volume after $72 \mathrm{~h}(\mathrm{ml})$ & $1590(450-3285)$ & $370(84-1365)$ & 0.002 \\
\hline Oliguria resolve time $(\mathrm{d})$ & $2.5(1.0-3.8)$ & $5(2.5-8.5)$ & 0.033 \\
\hline Complete renal recovery (\%) & $37 \%$ & $19 \%$ & 0.016 \\
\hline Time for complete renal recovery (d) & $13 \pm 9$ & $22 \pm 14$ & 0.042 \\
\hline Partial renal recovery (\%) & $9 \%$ & $15 \%$ & 0.409 \\
\hline RRT independence at discharge (\%) & $42 \%$ & $29 \%$ & 0.111 \\
\hline
\end{tabular}

Max $\mathrm{BUN}=$ maximum blood urea nitrogen, $\mathrm{Max} \mathrm{SCr}=$ maximum serum creatinine. 
Table 5 Hemodynamic parameters and adverse events within the first $\mathbf{7 2} \mathbf{h}$ of treatment

\begin{tabular}{|c|c|c|c|}
\hline & GDRRT $(n=70)$ & DHF $(n=70)$ & $P$ value \\
\hline Tachycardia (\%) & $60 \%$ & $79 \%$ & 0.018 \\
\hline MAP $(\mathrm{mmHg})$ & $82 \pm 12$ & $83 \pm 15$ & 0.664 \\
\hline Hypotension (\%) & $38 \%$ & $40 \%$ & 0.862 \\
\hline Blood coagulation (\%) & $21 \%$ & $37 \%$ & 0.041 \\
\hline Daily ultrafiltration volume (ml) & $2112 \pm 768$ & $1925 \pm 866$ & 0.179 \\
\hline \multicolumn{4}{|l|}{ Anticoagulant therapies } \\
\hline Unfractionated heparin & $5 \%$ & $20 \%$ & $<0.01$ \\
\hline LMWH & $28 \%$ & $60 \%$ & $<0.01$ \\
\hline No therapy & $67 \%$ & $20 \%$ & $<0.01$ \\
\hline Dialysate + filtration rate $(\mathrm{ml} / \mathrm{kg} / \mathrm{h})$ & $24.2 \pm 11.1$ & $63.7 \pm 12.6$ & \\
\hline
\end{tabular}

$\mathrm{MAP}=$ mean arterial pressure; $\mathrm{LMWH}=$ low-molecular-weight heparin.

dialysis as soon as possible [28,29]. But the use of higher dialysis dose doesn't appear to have a strong influence on renal recovery [9]. In our study, GDRRT led to significantly greater elimination of $\mathrm{BUN}$ and $\mathrm{SCr}$, along with correction of hyperkalemia (Table 4). GDRRT was mainly composed of bedside HD, which may correct azotemia and electrolyte disorders more effectively than DHF. Because of the flexibility of GDRRT regarding dose and treatment time, urinary volume after $72 \mathrm{~h}$ of treatment was much higher and oliguria resolved much faster in the GDRRT group, which may have resulted in better renal outcome.

Even though treatment with GDRRT did not result in a survival advantage over DHF, the complete renal recovery rate was significantly higher in the GDRRT group compared with the DHF group ( $37 \%$ vs. $19 \%, \mathrm{P}=0.016$ ) and less time was necessary for renal recovery (13.9 vs. 22.14 days, $\mathrm{P}=0.042$ ). The lack of a statistically significant difference in hospital mortality between the 2 groups might have been due to the small sample size. Furthermore, DHF is beneficial for sepsis, the incidence of which was higher in the DHF group, and this might have improved the overall outcome.

Our study has several limitations. It was a single-center study with a small sample size, and the time of the survey period may have had some influence on the result, due to changes in surgery procedures and other clinical treatments, but our in-hospital mortality rate was comparable to the previously published rates of $38.8 \%-59 \%$ for cardiac surgery RTT patients $[8,9,11,26]$.

\section{Conclusions}

Our results suggest that GDRRT is safe and effective for patients with AKI after cardiac surgery and is superior to DHF for improving renal recovery. In addition, it reduces hospitalization time and expenses. GDRRT can be applied to most AKI patients after cardiac surgery, while
DHF may be more suitable for critically ill AKI patients with sepsis or MODS.

\section{Abbreviations}

GDT: Goal directed therapy; EGDT: Early goal-directed fluid therapy; RRT: Renal replacement therapy; GDRRT: Goal-directed renal replacement therapy; DHF: Daily hemofiltration; HD: Hemodialysis; HF: Hemofiltration; HDF: Hemodiafiltration; AKl: Acute kidney injury; CRRT: Continuous renal replacement therapy;

IRRT: Intermittent renal replacement therapy; SLED: Sustained low-efficiency dialysis; ICU: Intensive care unit; APACHE: Acute physiology and chronic health evaluation; SOFA: Sepsis-related organ failure assessment; BUN: Blood urea nitrogen; SCr: Serum creatinine; MAP: Mean arterial pressure; CVP: Central venous pressure; LMWH: Low-molecular-weight heparin; ARDS: Acute respiratory distress syndrome; MODS: Multiple organ dysfunction syndrome; CABG: Coronary artery bypass graft; $\mathrm{CWH}$ : Continued veno-veno hemofiltration; ESRD: End-stage renal disease.

\section{Competing interests}

All authors declare that they have no competing interests.

\section{Authors' contributions}

JRX developed the study protocol, collected and analyzed the data, and wrote manuscript. XQD designed the study and provided critical review of the manuscript. YF provided critical review of the manuscript. BS and $\mathrm{ZHL}$ collected some of the data. JZZ designed the study and provided critical review of the manuscript. LL and CSW collected some of the data. JT conceived the study, developed the study protocol and provided critical review of the manuscript. All authors read and approved the final manuscript.

\section{Acknowledgements}

We would like to express our sincere gratitude to our colleagues whose name did not appear on the paper but also contributed to the article. We especially thank Wei Jin, Yan Xu, Yanyan Heng, Rong Xu, Hong Liu, Xiaomeng Cui, and Peiyi Lin for collecting the data, and Hao Chen and Shouguo Yang for conducting the study.

This work was supported by a grant from Key Projects in the National Science \& Technology Pillar Program in the Twelfth Five-year Plan Period (2011BAl10B07) and the Project of Technology Committee in Shanghai (12DJ1400200).

\section{Author details}

'Department of Nephrology, Zhongshan Hospital, Shanghai Medical College, Fudan University, No 180 Fenglin Road, Shanghai 200032, China. ${ }^{2}$ Shanghai Institute of Kidney and Dialysis, No 180 Fenglin Road, Shanghai 200032, China. ${ }^{3}$ Department of Cardiovascular Surgery, Zhongshan Hospital, Shanghai Medical College, Fudan University, No 180 Fenglin Road, Shanghai 200032, China. 
Received: 13 December 2013 Accepted: 13 June 2014

Published: 18 June 2014

\section{References}

1. Haase M, Shaw A: Acute kidney injury and cardiopulmonary bypass: special situation or same old problem? Contrib Nephrol 2010, 165:33-38.

2. Fang Y, Ding X, Zhong Y, Zou J, Teng J, Tang Y, Lin J, Lin P: Acute kidney injury in a Chinese hospitalized population. Blood Purif 2010, 30:120-126.

3. Rosner MH, Okusa MD: Acute kidney injury associated with cardiac surgery. Clin J Am Soc Nephrol 2006, 1:19-32.

4. Ghahramani N, Shadrou S, Hollenbeak C: A systematic review of continuous renal replacement therapy and intermittent haemodialysis in management of patients with acute renal failure. Nephrol (Carlton) 2008, 13:570-578.

5. Bagshaw SM, Berthiaume LR, Delaney A, Bellomo R: Continuous versus intermittent renal replacement therapy for critically ill patients with acute kidney injury: a meta-analysis. Crit Care Med 2008, 36:610-617.

6. Holt BG, White JJ, Kuthiala A, Fall P, Szerlip HM: Sustained low-efficiency daily dialysis with hemofiltration for acute kidney injury in the presence of sepsis. Clin Nephrol 2008, 69:40-46.

7. Ricci Z, Salvatori G, Bonello M, Pisitkun T, Bolgan I, D'Amico G, Dan M, Piccinni $P$, Ronco $C$ : In vivo validation of the adequacy calculator for continuous renal replacement therapies. Crit Care 2005, 9:R266-R273.

8. Bellomo R, Cass A, Cole L, Finfer S, Gallagher M, Lo S, McArthur C, McGuinness S, Myburgh J, Norton R, Scheinkestel C, Su S: Intensity of continuous renal-replacement therapy in critically ill patients. $N$ Engl J Med 2009, 361:1627-1638.

9. Palevsky PM, Zhang JH, O'Connor TZ, Chertow GM, Crowley ST, Choudhury D, Finkel K, Kellum JA, Paganini E, Schein RM, Smith MW, Swanson KM, Thompson BT, Vijayan A, Watnick S, Star RA, Peduzzi P: Intensity of renal support in critically ill patients with acute kidney injury. N Engl J Med 2008, 359:7-20.

10. Elahi M, Asopa S, Pflueger A, Hakim N, Matata B: Acute kidney injury following cardiac surgery: impact of early versus late haemofiltration on morbidity and mortality. Eur J Cardiothorac Surg 2009, 35:854-863.

11. Bapat V, Sabetai M, Roxburgh J, Young C, Venn G: Early and intensive continuous veno-venous hemofiltration for acute renal failure after cardiac surgery. Interact Cardiovasc Thorac Surg 2004, 3:426-430.

12. Demirkilic U, Kuralay E, Yenicesu M, Caglar K, Oz BS, Cingoz F, Gunay C, Yildirim V, Ceylan S, Arslan M, Vural A, Tatar H: Timing of replacement therapy for acute renal failure after cardiac surgery. J Card Surg 2004, 19:17-20.

13. Shoemaker WC, Montgomery ES, Kaplan E, Elwyn DH: Physiologic patterns in surviving and nonsurviving shock patients. Use of sequential cardiorespiratory variables in defining criteria for therapeutic goals and early warning of death. Arch Surg 1973, 106:630-636.

14. Dalfino L, Giglio MT, Puntillo F, Marucci M, Brienza N: Haemodynamic goal-directed therapy and postoperative infections: earlier is better. A systematic review and meta-analysis. Crit Care 2011, 15:R154.

15. Goepfert MS, Reuter DA, Akyol D, Lamm P, Kilger E, Goetz AE: Goal-directed fluid management reduces vasopressor and catecholamine use in cardiac surgery patients. Intensive Care Med 2007, 33:96-103.

16. Goepfert MS, Richter HP, Eulenburg CZ, Gruetzmacher J, Rafflenbeul E, Roeher K, Sandersleben AV, Diedrichs S, Reichenspurner H, Goetz AE, Reuter DA: Individually optimized hemodynamic therapy reduces complications and length of stay in the intensive care unit: a prospective, randomized controlled trial. Anesthesiology 2013, 19(4):824-836.

17. Lobo SM, de Oliveira NE: Clinical review: What are the best hemodynamic targets for noncardiac surgical patients? Crit Care 2013, 17:210.

18. Goldstein SL: Fluid management in acute kidney injury. J Intensive Care Med 2012, [Epub ahead of print][PMID:23753221]

19. Mehta RL: Continuous renal replacement therapy in the critically ill patient. Kidney Int 2005, 67:781-795.

20. Knaus WA, Draper EA, Wagner DP, Zimmerman JE: APACHE II: a severity of disease classification system. Crit Care Med 1985, 13:818-829.

21. Vincent JL, Moreno R, Takala J, Willatts $S$, De Mendonca A, Bruining H, Reinhart CK, Suter PM, Thijs LG: The SOFA (Sepsis-related Organ Failure Assessment) score to describe organ dysfunction/failure. On behalf of the Working Group on Sepsis-Related Problems of the European Society of Intensive Care Medicine. Intensive Care Med 1996, 22:707-710.

22. Roques F, Nashef SA, Michel P, Gauducheau E, de Vincentiis C, Baudet E, Cortina J, David M, Faichney A, Gabrielle F, Gams E, Harjula A, Jones MT,
Pintor PP, Salamon R, Thulin L: Risk factors and outcome in European cardiac surgery: analysis of the EuroSCORE multinational database of 19030 patients. Eur J Cardiothorac Surg 1999, 15:816-822. discussion 822-813.

23. Mehta RL, Kellum JA, Shah SV, Molitoris BA, Ronco C, Warnock DG, Levin A: Acute Kidney Injury Network: report of an initiative to improve outcomes in acute kidney injury. Crit Care 2007, 11:R31.

24. Bone RC, Balk RA, Cerra FB, Dellinger RP, Fein AM, Knaus WA, Schein RM, Sibbald WJ: Definitions for sepsis and organ failure and guidelines for the use of innovative therapies in sepsis. The ACCP/SCCM Consensus Conference Committee. American College of Chest Physicians/Society of Critical Care Medicine. Chest 1992, 101:1644-1655.

25. Honore PM, Joannes-Boyau O, Gressens B: Blood and plasma treatments: the rationale of high-volume hemofiltration. Contrib Nephrol 2007, 156:387-395.

26. Vidal S, Richebe P, Barandon L, Calderon J, Tafer N, Pouquet O, Fournet N, Janvier G: Evaluation of continuous veno-venous hemofiltration for the treatment of cardiogenic shock in conjunction with acute renal failure after cardiac surgery. Eur J Cardiothorac Surg 2009, 36:572-579.

27. Hsu CY: Linking the population epidemiology of acute renal failure, chronic kidney disease and end-stage renal disease. Curr Opin Nephrol Hypertens 2007, 16:221-226.

28. Hsu CY, Chertow GM, McCulloch CE, Fan D, Ordonez JD, Go AS: Nonrecovery of kidney function and death after acute on chronic renal failure. Clin J Am Soc Nephrol 2009, 4:891-898.

29. Macedo E, Bouchard J, Mehta RL: Renal recovery following acute kidney injury. Curr Opin Crit Care 2008, 14:660-665.

doi:10.1186/1749-8090-9-103

Cite this article as: Xu et al:: New, goal-directed approach to renal replacement therapy improves acute kidney injury treatment after cardiac surgery. Journal of Cardiothoracic Surgery 2014 9:103.

\section{Submit your next manuscript to BioMed Central and take full advantage of:}

- Convenient online submission

- Thorough peer review

- No space constraints or color figure charges

- Immediate publication on acceptance

- Inclusion in PubMed, CAS, Scopus and Google Scholar

- Research which is freely available for redistribution

Submit your manuscript at www.biomedcentral.com/submit 